\section{Magnetic Resonance Imaging: A Nondestructive Analytical Tool for Developmental Physiology}

Magnetic resonance imaging (MRI) is a powerful tool to visualize water in living organisms. It is used widely in medicine for locating abnormalities: however, the technique has been used less in plant science. Imaging is based on nuclear magnetic resonance (NMR) signals that are processed by a computer into visible images. NMR instruments excite water molecules, and relaxation times are measured as T1 or T2 times. $\mathrm{T} 1$ relaxation measures the time it takes to dissipate energy from the exited state of nuclei to their surroundings, the so-called "lattice." In the T2 relaxation process, no energy is transferred from the nuclei to the lattice. Rather, the nuclei in the exited state exchange energy with another nucleus in the ground state; i.e., while one nucleus releases energy, its neighbor absorbs it. T2 relaxation is more efficient, especially when large molecules are involved. T2 in free water is much longer than in bound water. Bound water is defined as an association between water and macromolecules. Details on MRI can be obtained from Wehrli (1988).

The power of the instrument depends on the magnetic field the instrument generates measured by units of Tesla $(T=10,000$ gauss). There are essentially three types of instruments used for MRI: 1.5-T units, used in medicine, with a large bore that can accomdate humans; 4.7-T units, which have a bore $30 \mathrm{~cm}$ in diameter and can accept potted plants; and 9.6-T units, which have a 5-cmdiameter bore and can be used only with plants or plant parts that fit into it. The illustrations on the front cover were imaged by a 9.6-T unit.

Imaging is based on the principle that free water molecules can be excited easily and relax slowly. In contrast, water molecules associated with macromolecules are difficult to excite and relax rapidly. Within any given tissue, depending on its structure, there are gradients of free water and the corresponding relaxation times create the image.

With woody plant tissues, it takes a long time to obtain good images. It usually requires 2 to $10 \mathrm{~h}$ to get a good, clean image. To increase repeatability, shorter times are used that create static, but the image is visible (Fig. 1). The signal-to-noise ratio depends on basic imaging parameters that cannot be dismissed. To obtain qualitative repeti-

Received for publication 25 Apr. 1991. The cost of publishing this paper was defrayed in part by the payment of page charges. Under postal regulations, this paper therefore must be hereby marked advertisement solely to indicate this fact. tion, images with noise are satisfactory. We were interested in whether the bud is visible or not in the images [see Faust et al. (1991) for detailed explanation (this issue)]. We could get a yes or no answer with shorter times. However, in most imaging, a clean image is necessary.

It is also desirable to measure the $\mathrm{T} 2$ times in milliseconds to get quantitative data. There are some problems in obtaining such data. Usually, it is possible to block out an area on the image and obtain a $\mathrm{T} 2$ value for the given area (Fig. 2). Because we work with very small structures, the $\mathrm{T} 2$ value obtained represents an average of several tissue types. In addition, the free water content is not uniform within a given structural element. This is clearly visible on Fig. 2, where various pixels show varying amounts of free water. If the tissue is large enough, an area from the uniformly bright area must be blocked out for $\mathrm{T} 2$ measurements, as illustrated in Fig. 3. Even though our T2 values in the bud increase from 6 to $10 \mathrm{~ms}$ and in the stem from 10 to $24 \mathrm{~ms}$ as the free water image increases, these values are far less than those obtained in mammalian tissues, which are typically between 50 and $100 \mathrm{~ms}$.

The front cover illustrates a cross section of an apple shoot and the adjoining lateral bud. The cultivar is Northern Spy and the buds are fully chilled. The larger circle is the cross section of the shoot and the pointed oval is the bud. In unchilled samples, the bud is not visible (Faust et al., 1991). The exact position where the image is located is illustrated by Faust et al. (1991, Fig. 1) on page 887. Most images are black-and-white; these are preferred because they are easiest to interpret. Brighter whites represent more free water in the tissue. The computer can also create color images. Color images have the disadvantage that a color code is necessary to interpret the image. In general, the brighter colors represent more free water. In the blue-yellow image it is the yellow; in the blue-white the white; in the purple-orange the orange, and the red-blue the blue that represents free water.

The MRI instrument used in these studies is located in the Environmental Chemistry Laboratory of the Beltsville Agricultural Research Center, Beltsville, Md. A team of scientists who collaborated in producing the images published here and elsewhere are composed of Miklos Faust, Research Leader, Fruit Laboratory, ARS, Beltsville; Gary W. Stutte, Associate Professor, and Dehua Liu, graduate student, Dept. of Horticulture, Univ. of Maryland, College Park; Merle M. Millard, research scientist, and Michael J. Line, electrical engineer, Environmental Chemistry Laboratory, ARS, Beltsville. The images on the cover were created by Michael Nine.

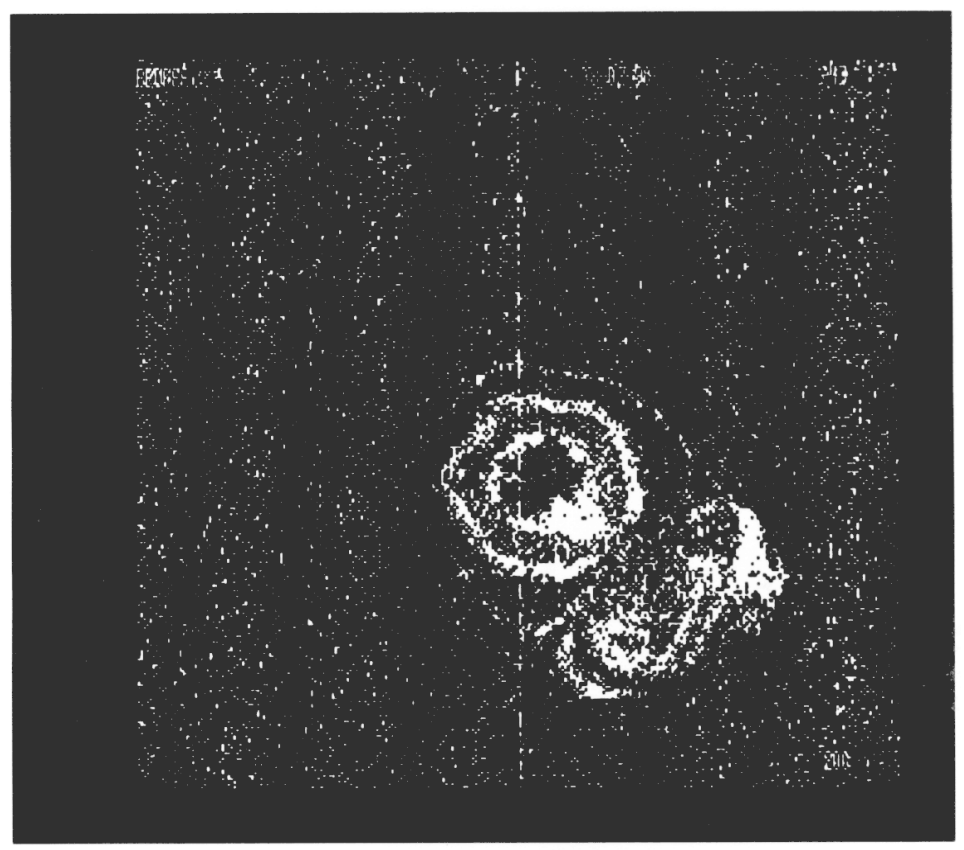

Fig. 1. Magnetic resonance image of apple bud and stem with high noise levels. These images are useful only for qualitative data. Note that in this chilled sample the bud is visible (smaller white circle), and therefore, contains free water.

(continued on inside back cover) 


\section{Literature Cited}

Faust, M., D. Liu, M.M. Millard, and G.W. Stutte. 1991. Bound versus free water in dormant apple buds-A theory for endodormancy. HortScience 26(7):887-890

Wherli, F.W. 1988. Principles of magentic resonance, p. 3-23. In: D. Stark and W.G. Bradley (eds.). Magnetic resonance imaging. Mosby, St. Louis.

Miklos Faust Beltsville Agricultural Research Center Agricultural Research Service Beltsville, MD 20705

Fig. 2. Magnetic resonance image of an apple stem section with bud. The bud is partially chilled and shows faintly in the image. Numbered areas represent the tissue where T2 times were measured. Note the heterogenecity of tissues within the block. Also note the various degrees of free water when pixels of the same tissue are compared.

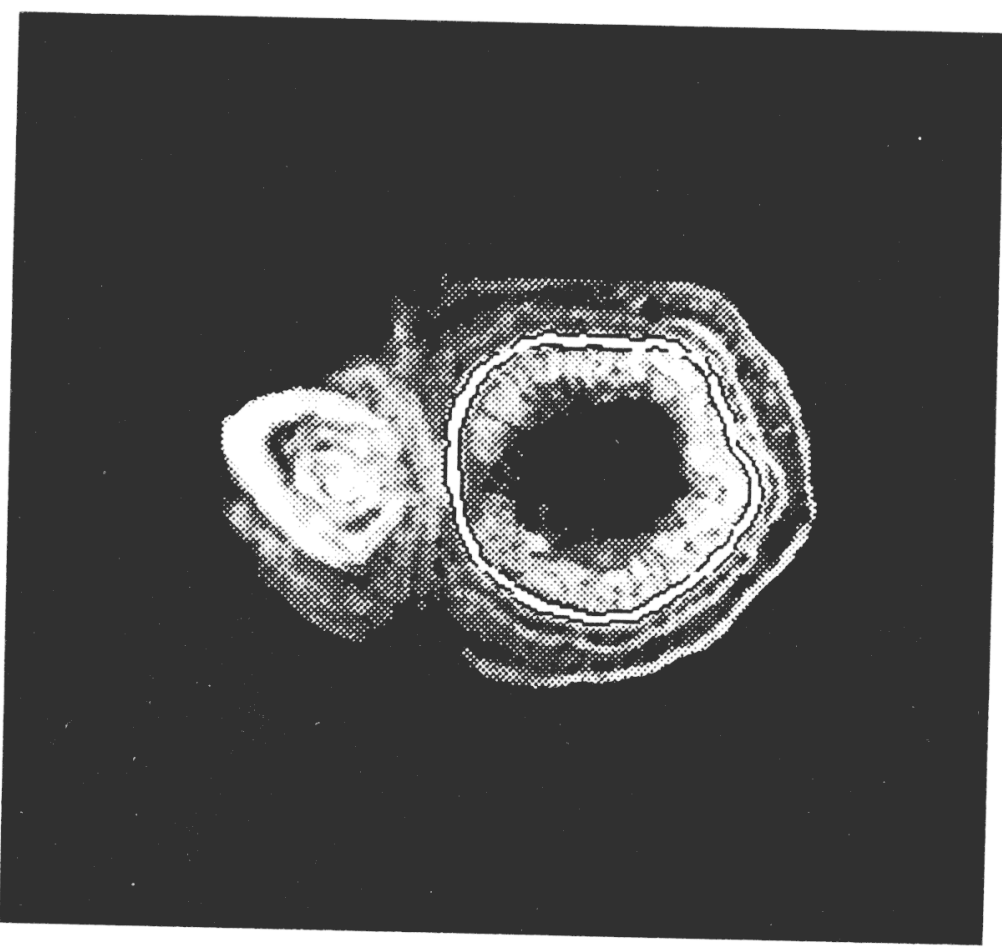

Fig. 3. Magnetic resonance image of apple stem and bud with area of uniform intensity between the two dark limes marking the approximate meristematic area for $\mathrm{T} 2$ measurements. 